\title{
Is laughter a better vocal change detector than a growl?
}

Citation for published version (APA):

Pinheiro, A. P., Barros, C., Vasconcelos, M., Obermeier, C., \& Kotz, S. A. (2017). Is laughter a better vocal change detector than a growl? Cortex, 92, 233-248. https://doi.org/10.1016/j.cortex.2017.03.018

Document status and date:

Published: 01/07/2017

DOI:

10.1016/j.cortex.2017.03.018

Document Version:

Publisher's PDF, also known as Version of record

Document license:

Taverne

Please check the document version of this publication:

- A submitted manuscript is the version of the article upon submission and before peer-review. There can be important differences between the submitted version and the official published version of record.

People interested in the research are advised to contact the author for the final version of the publication, or visit the DOI to the publisher's website.

- The final author version and the galley proof are versions of the publication after peer review.

- The final published version features the final layout of the paper including the volume, issue and page numbers.

Link to publication

\footnotetext{
General rights rights.

- You may freely distribute the URL identifying the publication in the public portal. please follow below link for the End User Agreement:

www.umlib.nl/taverne-license

Take down policy

If you believe that this document breaches copyright please contact us at:

repository@maastrichtuniversity.nl

providing details and we will investigate your claim.
}

Copyright and moral rights for the publications made accessible in the public portal are retained by the authors and/or other copyright owners and it is a condition of accessing publications that users recognise and abide by the legal requirements associated with these

- Users may download and print one copy of any publication from the public portal for the purpose of private study or research.

- You may not further distribute the material or use it for any profit-making activity or commercial gain

If the publication is distributed under the terms of Article $25 \mathrm{fa}$ of the Dutch Copyright Act, indicated by the "Taverne" license above, 


\title{
Research report
}

\section{Is laughter a better vocal change detector than a growl?}

\author{
Ana P. Pinheiro ${ }^{a, b, *}$, Carla Barros ${ }^{b}$, Margarida Vasconcelos ${ }^{b}$, \\ Christian Obermeier ${ }^{c}$ and Sonja A. Kotz ${ }^{c, d}$ \\ ${ }^{a}$ Faculty of Psychology, University of Lisbon, Lisbon, Portugal \\ ${ }^{\mathrm{b}}$ Neuropsychophysiology Laboratory, School of Psychology, University of Minho, Braga, Portugal \\ c Dept. of Neuropsychology, Max Planck Institute for Human Cognitive and Brain Sciences, Leipzig, Germany \\ ${ }^{\mathrm{d}}$ Faculty of Psychology and Neuroscience, Dept. of Neuropsychology \& Psychopharmacology, Maastricht University, \\ The Netherlands
}

\section{A R T I C L E I N F O}

Article history:

Received 19 September 2016

Reviewed 18 November 2016

Revised 26 January 2017

Accepted 27 March 2017

Action editor Ed Wilding

Published online 11 April 2017

Keywords:

Emotion

Voice

Prediction error

Mismatch negativity

Beta oscillations

\begin{abstract}
A B S T R A C T
The capacity to predict what should happen next and to minimize any discrepancy between an expected and an actual sensory input (prediction error) is a central aspect of perception. Particularly in vocal communication, the effective prediction of an auditory input that informs the listener about the emotionality of a speaker is critical. What is currently unknown is how the perceived valence of an emotional vocalization affects the capacity to predict and detect a change in the auditory input. This question was probed in a combined event-related potential (ERP) and time-frequency analysis approach. Specifically, we examined the brain response to standards (Repetition Positivity) and to deviants (Mismatch Negativity - MMN), as well as the anticipatory response to the vocal sounds (pre-stimulus beta oscillatory power). Short neutral, happy (laughter), and angry (growls) vocalizations were presented both as standard and deviant stimuli in a passive oddball listening task while participants watched a silent movie and were instructed to ignore the vocalizations. MMN amplitude was increased for happy compared to neutral and angry vocalizations. The Repetition Positivity was enhanced for happy standard vocalizations. Induced pre-stimulus upper beta power was increased for happy vocalizations, and predicted the modulation of the standard Repetition Positivity. These findings indicate enhanced sensory prediction for positive vocalizations such as laughter. Together, the results suggest that positive vocalizations are more effective predictors in social communication than angry and neutral ones, possibly due to their high social significance.
\end{abstract}

(c) 2017 Elsevier Ltd. All rights reserved.

\footnotetext{
* Corresponding author. Neuropsychophysiology Laboratory, CIPsi, School of Psychology, University of Minho, Campus de Gualtar, 4710957, Braga, Portugal.

E-mail address: ana.pinheiro@psi.uminho.pt (A.P. Pinheiro). 


\section{Introduction}

In a constantly changing environment humans face the challenge of having to prioritize sensations that compete for attention. Perception becomes more effective when sensory predictions are formed and updated based on the comparison of predicted and actual sensory feedback to minimize a prediction error (e.g., Arnal \& Giraud, 2012). The automatic nature of such a mechanism plays a critical role in social communication: as much of the sensory input in our daily life has an affective tone, our capacity to effectively respond to unpredicted changes based on their emotional salience significantly contributes to effective social interactions (Jessen \& Kotz, 2011; Jessen, Obleser, \& Kotz, 2012).

In social communication, the voice represents one of the most relevant sound categories (Belin, Fecteau, \& Bedard, 2004): it plays a pivotal role in conveying not only verbal information, but also important cues about the identity, age, and emotional state of a speaker (Belin, Bestelmeyer, Latinus, \& Watson, 2011). However, when compared to the study of facial emotion expressions, fewer studies have investigated the neural basis of vocal emotion processing. The existing studies support a multi-stage model of vocal emotional perception and recognition (Paulmann \& Kotz, 2008; Paulmann, Seifert, \& Kotz, 2010; Schirmer \& Kotz, 2006; Wildgruber, Ackermann, Kreifelts, \& Ethofer, 2006). An open question is how human listeners automatically detect saliency in vocalizations that may signal a change from an expected vocalization, and how the valence expressed by the voice (i.e., its perceived pleasantness us. unpleasantness e.g., Bradley \& Lang, 2000) influences this process. For instance, consider a mismatch between an angry vocalization and an utterance describing a happy event. The utterance will predict that the accompanying vocalization should be happy as well, but what you will hear is the opposite. The difference between how and when the vocal input occurs, and how it was expected to be is referred to as a prediction error leading to surprise, and a likely behavioral adaptation of a listener (e.g., Friston, 2012). As vocal information unfolds dynamically over time, the high temporal resolution of the electroencephalogram (EEG) is ideal to tackle these types of conflict in two ways: with a phase-locked evoked response and a nonphase locked oscillatory response. Specifically, pre-stimulus oscillatory activity may be better suited to probe how future auditory events are anticipated (e.g., Bernasconi, Manuel, Murray, \& Spierer, 2011; van Ede, Jensen, \& Maris, 2010), and therefore to shed light on the neurofunctional processes underlying the formation of a prediction.

\subsection{Detecting emotional change - insights from ERPs}

ERPs offer a unique glimpse into the temporal window of predictive effects in emotional voice processing. A commonly used electrophysiological event-related measure to estimate predictive processes is the Mismatch Negativity (MMN). The MMN is a negative ERP component that peaks at $100-250 \mathrm{msec}$ after sound onset, and signals the preattentive change detection in the sound environment (e.g., Näätänen, 1995, 2001). In MMN experiments participants are instructed to ignore a stream of sounds that differ in probability (highprobability or standard sounds us. low-probability or deviant sounds), and to focus their attention on a concurrent task such as watching a movie. Recent accounts of the functional significance of the MMN suggest that this component is a neurophysiological signature of predictive processing and, in particular, of a prediction error (e.g., Garrido, Kilner, Stephan, \& Friston, 2009). Two important processes seem to be at play. On the one hand, the detection of regularity in an auditory scene is required: the automatic extraction of statistical regularities (i.e., a frequently presented stimulus or standard sound) leads to increased top-down expectations, thereby resulting in suppressed neural responsiveness to the expected sound. In other words, the information about a frequently occurring stimulus is stored in a memory representation that then can facilitate predictions about what will happen next in an auditory environment. On the other hand, in the case of change detection, the mismatch between the top-down expectation and the perceived sensory input (i.e., a lowprobability stimulus or deviant sound) leads to a prediction error that enhances neural responsiveness to the unexpected sound. As such the MMN reflects the difference between topdown expectation and incoming bottom-up sensory signals, and represents a prediction error signal (Baldeweg, 2007; Garrido et al., 2009; Todd, Michie, Schall, Ward, \& Catts, 2012; Wacongne, Changeux, \& Dehaene, 2012; Winkler \& Czigler, 2012).

It is worth noting that some of the studies that used a passive roving standard stimulation to probe predictive processing have also revealed repetition effects to standard sounds that predicted the MMN elicitation (Baldeweg, 2007; Costa-Faidella, Baldeweg, Grimm, \& Escera, 2011; Haenschel, Vernon, Dwivedi, Gruzelier, \& Baldeweg, 2005). They showed that an increase in the number of stimulus repetitions resulted in an increase of the P50 and P2 amplitudes, which was termed 'Repetition Positivity'. These effects are typically observed in response to standard stimuli at frontocentral electrode sites from 50 to $250 \mathrm{msec}$ post-stimulus onset (Baldeweg, 2007; Costa-Faidella et al., 2011; Haenschel et al., 2005). They are proposed to reflect a neurophysiological correlate of a suppressed prediction error due to more efficient top-down predictions (Baldeweg, 2007).

The MMN may indicate how a change in emotional voice quality is detected preattentively. However, only a few MMN studies have investigated vocal emotional perception. The existing evidence confirms a rapid categorization of vocalizations based on their emotional relevance. Automatic distinctions of emotional vocalizations indexed by the MMN may be based on a minimal amount of acoustic information, such as mean F0 and its variation over time (Leitman, Sehatpour, Garidis, Gomez-Ramirez, \& Javitt, 2011). Schirmer and colleagues reported an earlier MMN peak latency for happy than for neutrally intoned pseudowords (Schirmer, Striano, \& Friederici, 2005), and a larger MMN amplitude for angry relative to neutral meaningless syllables that was positively correlated to state anxiety (Schirmer \& Escoffier, 2010). Chen and collaborators (Chen, Lee, \& Cheng, 2014) described a MMN amplitude increase for pseudowords expressing disgust compared to happiness. Using magnetoencephalography (MEG), Thonnessen et al. (2010) observed increased activation 
in the insula for happy relative to angry pseudowords. However, to the best of our knowledge, so far no study has investigated automatic emotional change detection with human vocalizations or affective bursts. As they lack segmental structure and semantic information (Kotchoubey, Kaiser, Bostanov, Lutzenberger, \& Birbaumer, 2009; Liu et al., 2012; Sauter \& Eimer, 2010) compared to emotionally inflected speech, vocalizations represent a more primitive expression of emotion (e.g., Belin et al., 2004). Compared to emotional speech prosody, vocalizations are associated with faster salience detection from acoustic cues, and lead to a more rapid emotional evaluation (e.g., Pell et al., 2015). Therefore, probing predictive processes in emotional vocalizations may lead to a better understanding of sensory change detection in emotional vocalizations devoid of concurrent lexical and phonological information, as it would typically be found in emotional speech.

\subsection{Detecting emotional change - insights from neural oscillatory activity}

Classical ERP analysis can be extended by the analysis of neural oscillations in the time-frequency domain, which reflects the trial-by trial dynamics of brain activity during sensory and cognitive processing (e.g., Roach \& Mathalon, 2008; Stothart \& Kazanina, 2013) and, more importantly, may indicate how participants predict when and what quality a stimulus may have before being exposed to the stimulus (e.g., Arnal \& Giraud, 2012; van Ede et al., 2010). Specifically, the analysis of oscillatory activity may provide critical insight into the mechanisms involved in change detection of emotional vocalizations that ERPs alone cannot provide. As the information contained in vocalizations is unfolding over time, and as there is no clear emotion recognition point, the information provided by non-phase locked neural oscillatory changes in EEG power is of particular interest (e.g., Jessen \& Kotz, 2011; Jessen et al., 2012). Therefore, the analysis of induced neural oscillations represents a meaningful approach to understand the brain mechanisms underlying the detection of regularities and change in emotional vocalizations. Specifically, prestimulus activity may be better suited to probe the effects of top-down expectations ${ }^{1}$ on emotional voice perception, i.e., on how future vocal events are anticipated (e.g., Bernasconi et al., 2011; Geerligs \& Akyürek, 2012; Weisz et al., 2014). Previous studies found that the state of the brain before an event influences the neural response to this event. For example, prestimulus neural oscillations in the beta-band were found to be modulated by top-down expectations (van Ede et al., 2010), to predict perception performance (Hanslmayr et al., 2007; Lange, Halacz, Van Dijk, Kahlbrock, \& Schnitzler, 2012), and to specifically facilitate temporal integration (Geerligs \& Akyürek, 2012), or temporal order judgment accuracy (Bernasconi et al., 2011). These studies agree that pre-stimulus neural oscillations inform about stimulus anticipation, a cornerstone of predictive coding in the context of emotional vocalizations.

\footnotetext{
${ }^{1}$ Here understood as a "neural state of learned readiness to experience events with particular characteristics" (Todd et al., 2012, p. 223).
}

Most of the studies that probed the effects of emotion on neural oscillations (reviewed in Symons, El-Deredy, Schwartze, \& Kotz, 2016) have used visual stimuli and focused on phase-locked (evoked) oscillations (e.g., Balconi \& Mazza, 2009; Güntekin \& Başar, 2010; Keil et al., 2001; Müller, Keil, Gruber, \& Elbert, 1999). Studies that probed the effects of emotion in the time-frequency domain using dynamic stimuli reported consistent effects in the beta frequency band. A stronger suppression of non-phase-locked beta power (15-25 Hz, $200 \mathrm{msec}$ post-stimulus onset) was observed for emotional (fearful and angry) compared to neutral audiovisual stimuli (Jessen \& Kotz, 2011). Probing change detection in emotional prosody, Chen and collaborators (Chen, Pan, Wang, Zhang, \& Yuan, 2015) observed a decrease of event-related spectral perturbation (phase-locked to stimulus onset) in the beta band (18-26 Hz) between 400 and $750 \mathrm{msec}$ to vocal emotional change (neutral-to-angry and angry-to-neutral) under explicit task instructions. Of note, these three studies (Chen et al., 2015; Jessen \& Kotz, 2011; Jessen et al., 2012) did not include a positive stimulus. Contrasting positively and negatively valenced musical chords, two studies (Omigie et al., 2015; Sammler, Grigutsch, Fritz, \& Koelsch, 2007) found a decrease in phase-locked beta power $(13-20 \mathrm{~Hz}$, event-related spectral perturbation) for dissonant (negatively valenced) relative to consonant (positively valenced) musical chords around $800 \mathrm{msec}$ and around $1300 \mathrm{msec}$ after stimulus onset. These findings highlight the sensitivity of beta oscillations to the emotional salience of a stimulus. ${ }^{2}$ In particular, non-phase locked beta oscillations can clarify how listeners anticipate the expected quality of a vocal stimulus as they bear no constant time and phase relationship with the eliciting vocal event, contrary to phase-locked oscillations that can be masked by ERPs (e.g., Deiber et al., 2007).

Besides their critical function in emotional processes, beta oscillations have also been associated with deviance processing. In particular, decreased beta power or desynchronization has been linked to the detection of an unexpected deviant event (e.g., Chen et al., 2015; Kim \& Chung, 2008), while an increase in beta-band activity or synchronization has been proposed to indicate that a current cognitive and motor state is maintained and, as such, reflects a top-down effect (e.g., Engel \& Fries, 2010). Both processes, the extraction of regularities or the adaptation to change in an auditory scene, are characteristic of emotional processes in communication. Critically, none of these studies looked at oscillatory processes

\footnotetext{
2 Please note that low and high frequencies in the beta range (low us. high beta or beta 1: $13-18 \mathrm{~Hz}$, beta 2: $19-25 \mathrm{~Hz}$, beta 3 : 26-30 Hz; reviewed in Weiss \& Mueller, 2012) are thought to reflect different cognitive operations (e.g., Shahin, Picton, \& Miller, 2009). Whereas low beta (13-20 Hz) effects have been related to the maintenance of information in working memory and temporal binding of segregated events - i.e., unification (e.g., Bastiaansen, Magyari, \& Hagoort, 2010; Lewis et al., 2015), effects in the upper range of the beta band $(25-30 \mathrm{~Hz})$ were associated with template matching in auditory memory in an oddball task (e. g., Shahin et al., 2009). For example, this may be critical for the cortical maintenance of memory representations of vocal sounds, which is necessary for the higher-order cognitive evaluation of their emotional significance. However, the functional role of low us. high beta remains to be clarified when a task involves the prediction of emotional cues.
} 
that take place before a vocal stimulus onset. Thus, the question arises whether anticipatory processes in vocal perception are modulated by emotion, and how this modulates change detection.

\subsection{Valence effects in voice processing}

The differentiation between neutral and emotional cues occurs rapidly in the brain, within $200 \mathrm{msec}$ after stimulus onset (e.g., Liu et al., 2012; Paulmann \& Kotz, 2008; Pell et al., 2015; Pinheiro et al., 2013, 2014). While a general increase of the ERP amplitude was observed for neutral compared to emotional prosodic stimuli irrespective of valence (e.g., Paulmann \& Kotz, 2008), other studies revealed that auditory processing may be differentially modulated by valence types earlier on (e.g., an increased P50 response to angry relative to neutral and happy vocalizations - Liu et al., 2012). However, it remains unclear whether positive and negative emotions affect prediction and change detection differently. In the current study, we focused on happy (laughter) and angry (growls) vocalizations as they are recognized crossculturally and above chance (Laukka et al., 2013). Also, they have similar acoustic profiles, such as high intensity and variable F0, which allows to easily distinguish them from other emotions (Hawk, van Kleef, Fischer, \& van der Schalk, 2009; Schröder, 2003). As shown in previous studies (Johnstone, van Reekum, Oakes, \& Davidson, 2006; Warren et al., 2006; reviewed in Scott, Lavan, Chen, \& McGettigan, 2014), positive vocalizations, such as laughter, represent particularly salient social signals, as they are highly relevant for social bonding. Johnstone and collaborators (Johnstone et al., 2006) compared brain activation to happy and angry vocalizations and found increased activation in the temporal cortex and in the right inferior frontal gyrus, as well as in the left insula and left amygdala, in response to happy compared to angry vocalizations. Consistent with the high (social) relevance of happy vocalizations at least in nonclinical populations, Sergerie, Chochol, and Armony (2008) reported increased amygdala activation for positive compared to negative stimuli in their meta-analysis of fMRI research of emotion processing. Warren et al. (2006) demonstrated that passively listening to positive vocal emotions (e.g., laughter) was associated with increased activation in the posterior left inferior frontal gyrus (IFG) compared to negative vocal emotions (fear and disgust). The authors proposed that positive valence expressed in the voice (amusement [i.e., laughter] and cheers of triumph) is related to a greater propensity for the activation of motor representations encoded in the posterior IFG (the hemodynamic responses were positively correlated with increasing positive valence). The enhanced motor activation may provide a mechanism for mirroring positive emotional states (i.e., empathic responses) in social interactions. These studies indicate that, contrary to the common view that negative emotions are more salient due to their evolutionary significance (e.g., Smith, Cacioppo, Larsen, \& Chartrand, 2003), positive emotions, at least in the auditory domain, may override negative emotions in attracting resources due to their high social significance (e.g., Scott et al., 2014).

\subsection{The current study and hypotheses}

The current study aimed at probing the effects of vocal emotions on forming predictions about the auditory environment and on automatic change detection. Hence, we used a modified oddball task, in which probability and valence were manipulated: neutral and emotional vocalizations (happy and angry) were presented both as high-probability (standard) and low-probability (deviant) task-irrelevant stimuli in an unattended sound sequence in different experimental blocks to the same participants. This procedure eliminates effects of acoustic differences between neutral and emotional stimuli as each sound serves as its own acoustic control (e.g., Jacobsen \& Schröger, 2003; Leitman et al., 2011). Further, the selected emotional vocalizations did not differ in perceived arousal. As emotional vocalizations are expressed almost automatically in social situations, implicit rather than explicit emotional processing paradigms are closer to real-life settings.

A combined ERP and time-frequency approach was utilized to investigate the mechanisms underlying implicit emotional voice processing within a predictive coding framework. Next to the analysis of phase-locked ERP signals, we also examined non-phase locked (induced) oscillations that provide clues about top-down mechanisms (e.g., Tallon-Baudry \& Bertrand, 1999), which play a critical role in prediction. Our analysis focused both on MMN difference waveforms, as well as on EEG activity to standard and deviant stimuli separately, to shed light on predictive processes associated with the representation of regularities in vocal stimulation (Repetition Positivity), and on the detection of a prediction error (MMN). Although repetition suppression effects have been widely described in auditory neuroscience, to date no study has attempted to explore the interactions between stimulus repetition and saliency at the electrophysiological level. Therefore, we examined how the prediction of a forthcoming vocal sound was modulated by the number of previous stimulus repetitions (standard ERP amplitude). In the analysis of neural oscillatory activity, we were mainly interested in pre-stimulus activity that modulates pre-attentive processing of emotional vocal cues. In light of current evidence on the role of beta activity in anticipation and prediction (Engel \& Fries, 2010), a special emphasis was placed on pre-stimulus beta power.

We expected predictive processes to be facilitated by the emotional quality of the vocalizations (e.g., Leitman et al., 2011; Schirmer et al., 2005). Specifically, we hypothesized that valence-specific differences would modulate the predictive processes indexed by the MMN, the Repetition Positivity, and by pre-stimulus beta oscillatory activity. Two competing hypotheses were tested. If predictive processes are facilitated by the negative valence of vocalizations (i.e., threat-related cues associated with avoidance), we expected an increase in MMN amplitude for unexpected (deviant) growls compared to laughter. This would also be evident in an increased Repetition Positivity for standard negative vocalizations. If, instead, predictive processes are enhanced for positive vocalizations (i.e., affiliation-related cues associated with approach), we expected to observe an increased MMN for unexpected (deviant) laughter relative to growls, as well as an increased Repetition Positivity in response to positive standard 
vocalizations. We also expected to observe increased prestimulus beta induced power as a function of increased predictability of the emotionally tagged vocalizations.

\section{Method}

\subsection{Participants}

Participants were 23 healthy college students (14 females; $23.00 \pm 3.17$ years; $14.96 \pm 3.13$ years of education). The inclusion criteria were: European Portuguese as first language; right handedness (Oldfield, 1971); no history of neurological illness; no history or current psychiatric disorder, as assessed by the Brief Symptom Inventory (Portuguese version Canavarro, 1999); no present medication for medical disorders that could have deleterious effects on EEG morphology; no hearing, vision, or upper body impairment - relevant for neuropsychological function. Participants were given course credit for their participation in the study, and provided written informed consent for the experimental protocol approved by a local Ethical Committee.

\subsection{Stimuli}

Stimuli were exemplars of a female vocalization, ${ }^{3}$ varying in emotional quality: happy (laughter), angry (growls), and neutral vocalizations (the vowel ah -/a/with neutral intonation). The sounds were selected from the Montréal Affective Voices (MAV) battery of non-verbal emotional vocalizations (Belin, Fillion-Bilodeau, \& Gosselin, 2008), after validation in a sample of European Portuguese participants $(n=60)$, who did not participate in the EEG study (Supplementary Table 1). These participants listened to each vocalization via loudspeakers and rated its valence (ranging from 1-"extremely unpleasant" to 9-“extremely pleasant"), arousal (ranging from 1-"extremely calm" to 9-"extremely aroused"), and dominance (ranging from 1-"totally controlled" to 9-"totally in control"), using the 9-point SAM scale (Bradley \& Lang, 1994). The duration of the MAV vocalizations (Belin et al., 2008) was shortened to $700 \mathrm{msec}$ but their emotional content was preserved (duration was the same for all vocal sounds presented in the current study). Stimuli were normalized in mean intensity $(70 \mathrm{~dB})$ using a Praat script (Boersma \& Weenink, 2013). A description of the acoustic properties of each vocalization can be found in Table 1.

\subsection{Procedure}

Each participant sat comfortably at a distance of $100 \mathrm{~cm}$ from a desktop computer monitor in a sound-attenuated and electrically shielded room. Vocalizations were presented in four blocks separated by brief rest periods, either as standard or deviant sounds to eliminate the effects of physical

\footnotetext{
${ }^{3}$ The experimental stimuli included neutral, happy (laughter) and angry (growl) exemplars of a female voice only, based on previous studies reporting rapid emotional decoding within the first $200 \mathrm{msec}$ after a vocal stimulus onset independent of speaker's voice, i.e., male or female (e.g., Paulmann \& Kotz, 2008).
}

Table 1 - Acoustic properties of the experimental stimuli.

\begin{tabular}{llcc}
\hline Acoustic properties & \multicolumn{3}{c}{ Vocalization } \\
\cline { 2 - 4 } & Neutral & $\begin{array}{c}\text { Happy } \\
\text { (Laughter) }\end{array}$ & $\begin{array}{c}\text { Angry } \\
\text { (Groal) }\end{array}$ \\
\hline $\begin{array}{c}\text { Mean F0 (Hz) } \\
\text { Averaged pitch } \\
\quad \text { contour (Hz) }\end{array}$ & $\begin{array}{l}190.57 \\
\text { Pitch onset } \\
\quad \text { time (msec) }\end{array}$ & 341.27 & 397.52 \\
$\begin{array}{c}\text { Intensity onset } \\
\text { time (msec) } \\
\begin{array}{c}\text { Maximum pitch } \\
\text { time (msec) }\end{array}\end{array}$ & 20.33 & 20.18 & 398 \\
$\begin{array}{c}\text { Maximum amplitude } \\
\text { time (msec) }\end{array}$ & 280.33 & 46.18 & 46.19 \\
\hline
\end{tabular}

differences between the stimuli (Fig. 1; Block $1=$ neutral standards, happy deviants; Block 2 = happy standards, neutral deviants; Block 3 = neutral standards, angry deviants; Block 4 = angry standards, neutral deviants). Each block contained 1200 stimuli: 1050 standard $(p=.875)$ and 150 deviant $(p=.125)$ vocalizations. The inter-stimulus interval (ISI) was $500 \mathrm{msec}$ following previous studies (Schirmer et al., 2005).

Stimuli were presented in a pseudo-randomized order with a minimum of six standards occurring between each deviant. The experimental blocks were counterbalanced across participants. The presentation and timing of stimuli were controlled through Presentation software (version 16.3; Neurobehavioral Systems, Inc.). Auditory stimuli were presented via Sennheiser CX 300-II headphones. While listening to the stimuli, participants were instructed to watch a silent movie (with neutral content - nature videos), and to ignore the auditory stimuli. They were also told they would be asked questions about the movie they watched at the end of the session. The movie was presented on a LG ACPI x86-based computer. At the end of the experimental sessions, participants rated the valence, arousal, and dominance of each vocalization using a 9-point SAM scale (Bradley \& Lang, 1994).

\subsection{EEG data acquisition and analysis}

EEG data were recorded using a 64-channel BioSemi Active Two system in a continuous mode at a digitization rate of $512 \mathrm{~Hz}$, and stored on disk for later analysis. Eye blinks and movements were monitored through electrodes placed on both temples (horizontal electrooculogram), and another one below the left eye (vertical electrooculogram). The offset of all electrodes was kept below $40 \mathrm{mV}$. Eye blinks and movements were monitored by electrodes placed on both temples (horizontal electrooculagram), and another one below the left eye (vertical electrooculogram). During data acquisition, the activity at all channels was referred to the system's internal loop (CMS/DRL sensors).

EEG data were analyzed using EEGLAB 13.1.1b software (Delorme \& Makeig, 2004) and in-house developed Matlab functions (The Mathworks). Data were referenced offline to the average of the left and right mastoids and high-pass, before applying a high-pass filter with a half-amplitude cutoff value of .1 Hz. Individual ERP epochs were created for each 

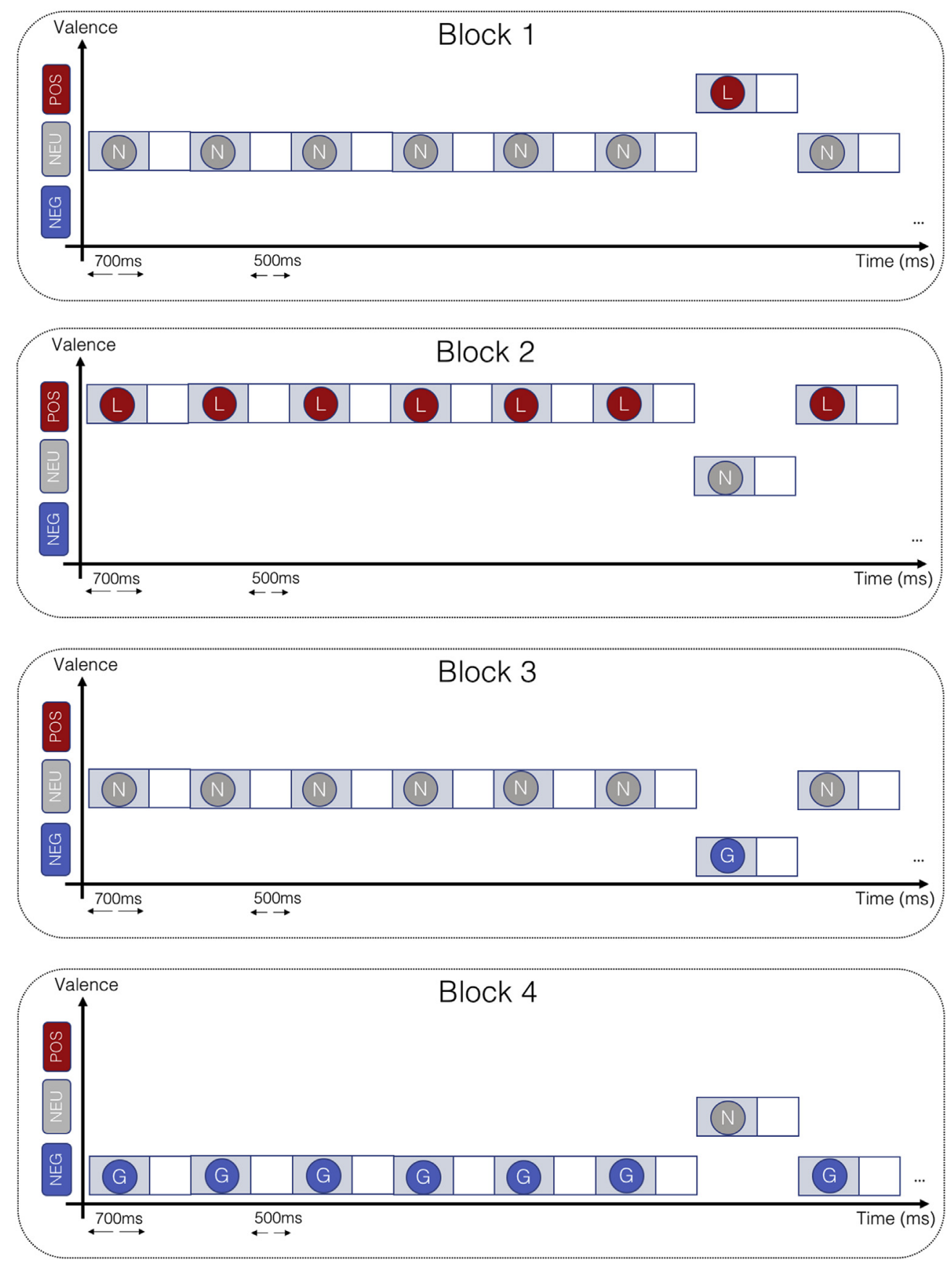

Fig. 1 - Schematic illustration of the experimental design.

stimulus type, with a $500 \mathrm{msec}$ pre-stimulus baseline up to $700 \mathrm{msec}$ post-stimulus epoch. Segments were screened for eye movements, muscle artifacts, electrode drifting and amplifier blocking. An independent component analysis was used to remove ocular and muscle artifacts (e.g., Hipp \& Siegel, 2013; Keren, Yuval-Greenberg, \& Deouell, 2010). EEG epochs with amplitudes exceeding $\pm 100 \mu \mathrm{V}$ were rejected. After artifact rejection, at least $84 \%$ of the segments per condition per participant entered the analyses. Conditions did not differ in the number of non-rejected epochs $(p>.05)$. To ensure the balance between the number of standard and deviant sounds, only the standard sounds immediately preceding a given deviant were included in subsequent analyses.

\subsubsection{ERP analyses}

For ERP analyses, the EEG was baseline corrected using the -200 to 0 msec pre-stimulus interval. Neural activity related to deviance detection was derived from the MMN. Difference waveforms were formed by subtracting ERP activity to a given vocalization when presented as standard in one experimental block from that elicited by the same vocalization when presented as a deviant in another block (e.g., Leitman et al., 2011; Schirmer et al., 2005). We selected a window of interest based on previous literature (Chandrasekaran, Krishnan, \& Gandour, 2007; Chen et al., 2014; Schirmer \& Escoffier, 2010), and on visual inspection of the waveforms over all conditions, all participants, and all scalp electrodes. The waveforms revealed 
that the MMN peaked between 160 and $230 \mathrm{msec}$ following stimulus onset for all electrodes, conditions, and participants. This ensured that the data selection method was not influenced by any condition-specific information at this stage of the analysis, thus avoiding "double dipping" in the statistical analysis (Kriegeskorte, Simmons, Bellgowan, \& Baker, 2009). Individual MMN amplitudes were quantified by extracting the mean amplitude voltage during the 160-230 msec interval.

Moreover, in order to get a more accurate view of how each vocalization was processed when presented as the frequent (i.e., predicted) or infrequent (i.e., not predicted) stimulus, we compared the amplitude for each vocalization as a standard and as a deviant in the MMN latency window.

In order to examine the Repetition Positivity elicited by standards, we based our quantification method on the previous literature (Baldeweg, 2007; Costa-Faidella et al., 2011; Haenschel et al., 2005) and on the inspection of grand average waveforms over all conditions, all participants, and all scalp electrodes. Mean amplitude was extracted in two latency windows of $80-160 \mathrm{msec}$ (P50) and 180-260 msec (P2) for standards, as a function of the number of repetitions in the global sequence. As the current study did not use a roving standard stimulation (contrary to previous studies that looked at the Repetition Positivity - e.g., Costa-Faidella et al., 2011; Haenschel et al., 2005), repetition effects were investigated by dividing the sequence of sounds in 5 blocks on the basis of cumulative frequency: block 1 included the averaged activity to the first $10 \%$ of standard presentations; block 2 included the first $25 \%$ of standard presentations; block 3 included the first $50 \%$ of standard presentations; block 4 included the first $75 \%$ of standard presentations; block 5 included $100 \%$ of standard presentations. Amplitudes in the two intervals (P50 and P2) were averaged for the five stimulus blocks.

\subsubsection{Time-frequency analyses}

Time frequency decomposition was performed using the Morlet wavelet transform (with a time-frequency relation of $m=7$ ), applied in $.25 \mathrm{~Hz}$ steps from 4 to $100 \mathrm{~Hz}$ at each time point to yield time-frequency (TF) maps of induced power. The wavelet frequency/duration ratio $(c=f 0 / \sigma f)$ was 7 and its multiplication factor $(\mathrm{m})$ was 4 . Baseline activity $(-500$ to $-250 \mathrm{msec}$ ) was subtracted from each TF map following the recommendations by Cohen (2016). The analysis of the nonphase-locked activity involved transforming each trial to the frequency domain and averaging the resulting wavelet transforms. We focused on the change in induced power relative to a pre-stimulus baseline of $200 \mathrm{msec}(-200$ to $0 \mathrm{msec}$ ) in the range of $13-30 \mathrm{~Hz}$ (beta-band).

\section{Results}

\subsection{Behavior}

Paired samples t-tests were performed to test differences between valence, arousal, and dominance ratings for the three vocalizations. Considering valence, angry vocalizations (growls) were rated as more unpleasant than neutral $[t(22)=6.146$, $p<.001]$ and happy (laughter) vocalizations $[\mathrm{t}(22)=-11.535$, $p<.001]$, while happy vocalizations were rated as more pleasant
Table 2 - Affective ratings of the experimental stimuli by the participants.

\begin{tabular}{lccc}
\hline \multirow{2}{*}{ Type of vocalization } & \multicolumn{3}{c}{ Affective dimension } \\
\cline { 2 - 4 } & Valence & Arousal & Dominance \\
\hline Neutral & $4.70(.78)$ & $3.09(1.35)$ & $7.04(1.85)$ \\
Happy (Laughter) & $7.96(.98)$ & $6.22(1.83)$ & $7.04(1.67)$ \\
Angry (Groal) & $2.52(1.70)$ & $6.83(1.40)$ & $3.96(1.69)$ \\
\hline Note: M (SD) values are shown. Values range from 1 to 9: a) valence: \\
$1=$ "extremely unpleasant", 9 = "extremely pleasant"; b) arousal: \\
$1=$ "extremely calm", $9=$ "extremely aroused"; c) dominance: \\
$1=$ "totally controlled", $9=$ "totally in control". \\
\hline
\end{tabular}

than the neutral ones [t(22) $=10.575, p<.001]$. Regarding arousal, neutral vocalizations were rated as less arousing than both angry $[\mathrm{t}(22)=-12.086, p<.001]$ and happy vocalizations $[\mathrm{t}(22)=-6.696, p<.001]$, but no differences were observed in arousal ratings of happy and angry vocalizations $(p>05)$. For dominance, angry vocalizations received the lowest dominance scores compared to both neutral $[\mathrm{t}(22)=6.95, p<.001]$ and happy vocalizations $[\mathrm{t}(22)=-7.094, p<.001]$ (see Table 2).

\subsection{Effects of stimulus status and emotion on the MMN}

A regions-of-interest (ROIs) analysis was applied using four ROIs: frontal (Fz, F3, F4), frontocentral (FCz, FC3, FC4), central $(\mathrm{Cz}, \mathrm{C} 3, \mathrm{C} 4)$, and centroparietal (CPz, CP3, CP4). MMN mean amplitude and peak latency were separately analyzed by a repeated-measures analysis of variance (ANOVA) with valence (neutral, happy [laughter], angry [growls]) and ROI as within-subject factors. All analyses were corrected for nonsphericity using the Greenhouse-Geisser method (the original $d f$ is reported). All significance levels are two-tailed with the present significance alpha level of $p<.05$. Main effects and interactions were followed with pairwise comparisons between conditions, using the Sidak adjustment for multiple comparisons. The effect sizes are shown as partial etasquared $\left(\eta_{\mathrm{p}}^{2}\right)$.

Confirming the frontocentral distribution of the $\mathrm{MMN}$ (Fig. 2), a ROI effect $\left[F(3,66)=20.680, p<.001, \eta_{\mathrm{p}}^{2}=.485\right]$ revealed a generally increased (i.e., more negative) amplitude in the frontocentral region relative to the central $(p=.010)$ and centroparietal $(p<.001)$ regions. Differences in MMN amplitude occurred as a function of valence and region [valence by ROI interaction $\left.-F(6,132)=2.610, p=.020, \eta_{p}^{2}=.106\right]$. This interaction was followed up with separate ANOVAs for each region separately. In the central ROI [valence effect $-F(2$, $\left.21)=4.263, p=.028, \eta_{\mathrm{p}}^{2}=.289\right]$, MMN was enhanced for happy relative to angry vocalizations $(p=.029)$. In the centroparietal ROI [valence effect $-F(2,21)=5.437, p=.013, \eta_{\mathrm{p}}^{2}=.341$ ], MMN was enhanced for happy relative to both neutral $(p=.05)$ and angry $(p=.018)$ vocalizations. ${ }^{4}$ Furthermore, MMN peaked

\footnotetext{
${ }^{4}$ Even though the P3a component was not the major focus in the current study, and as such no specific predictions were formulated, the amplitude of this component was also analyzed in the $260-330$ msec latency window. The P3a is elicited by taskirrelevant rare or novel stimuli, which is related to attention orienting, with its amplitude increasing as a function of stimulus salience (e.g., Nittono, 2006). The statistical analysis did not yield a significant valence effect $[F(2,44)=1.348, p>.05]$.
} 

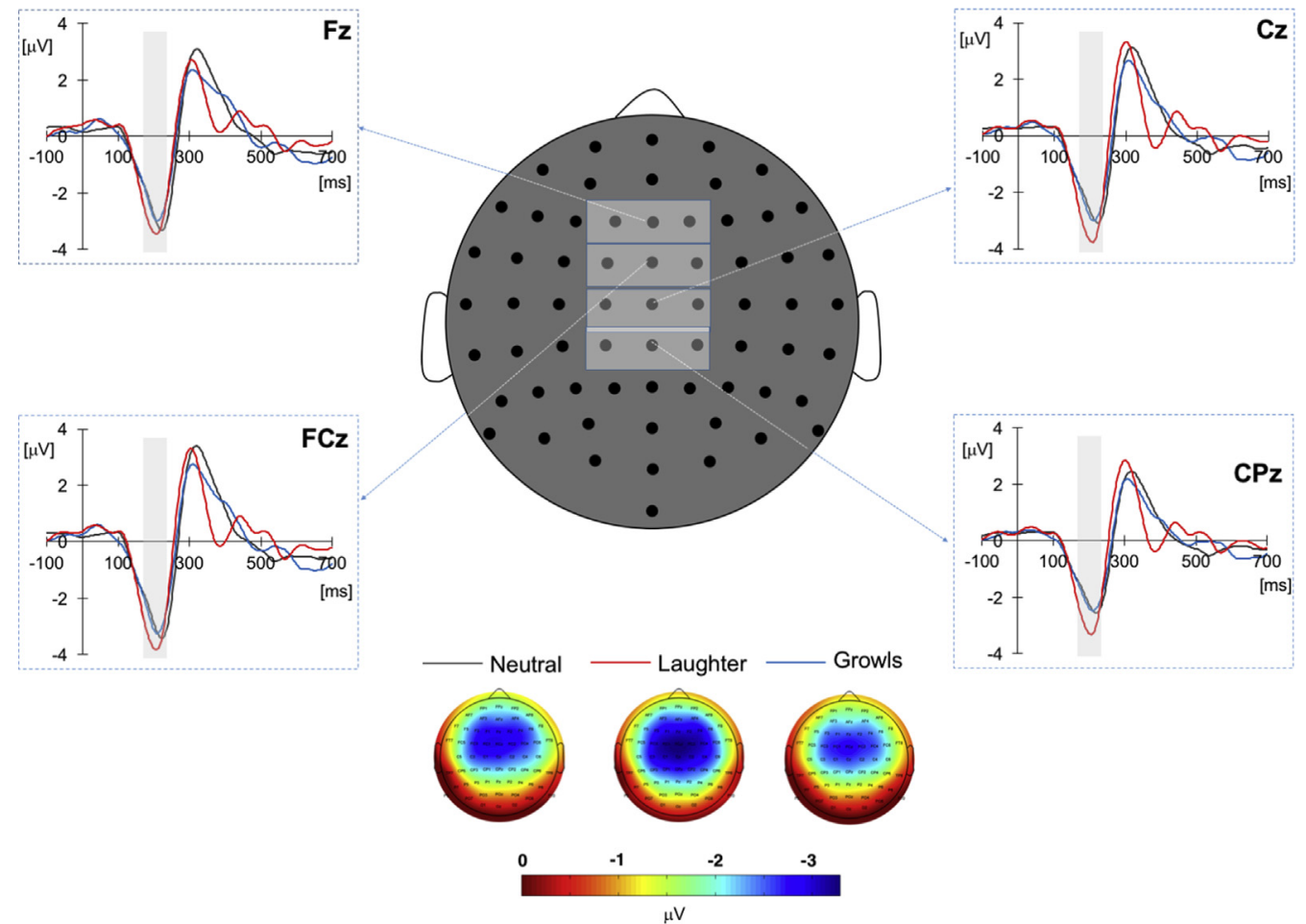

Fig. 2 - Grand average difference waveforms for neutral, happy (laughter), and angry (growls) vocalizations at midline electrodes.

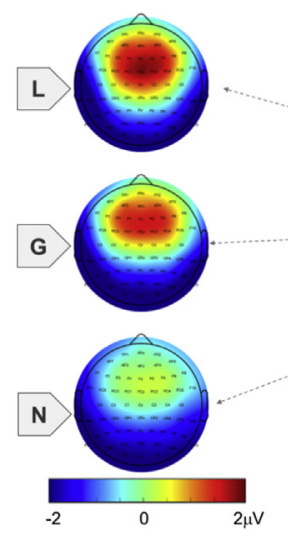

\section{Standard}

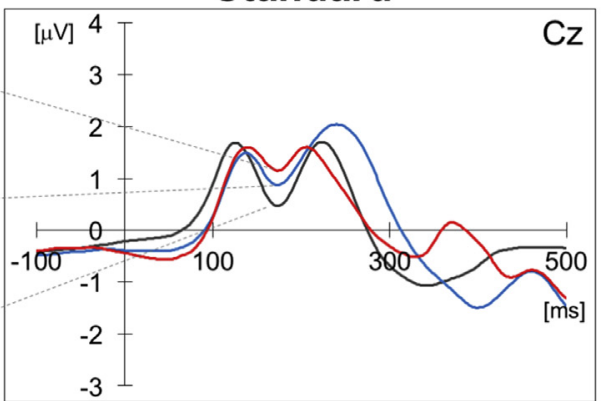

\section{Deviant}
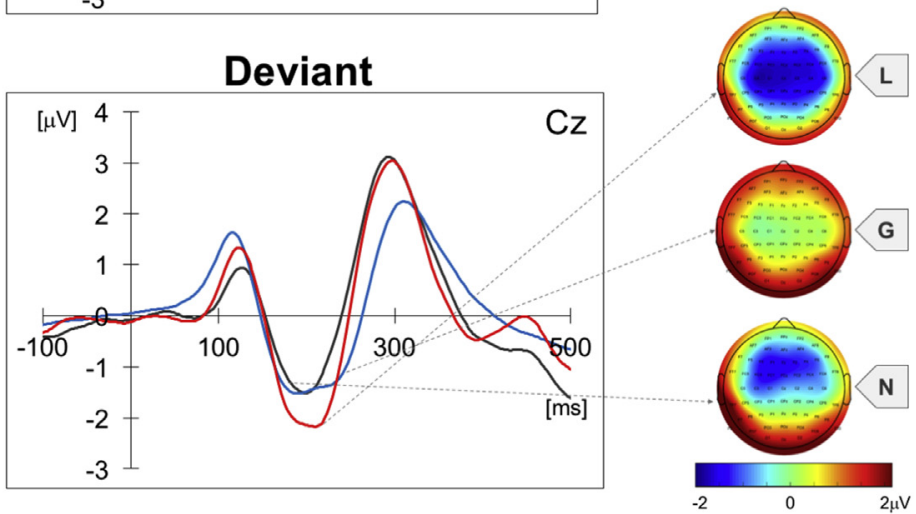

Fig. 3 - Grand average waveforms for standard and deviant vocalizations with neutral, positive (laughter), and negative (growls) valence. 
earlier for happy relative to neutral vocalizations $(p=.030)$, as indicated by a significant effect of valence $[F(2,44)=3.785$, $\left.p=.030, \eta_{\mathrm{p}}^{2}=.147\right]$.

An amplitude analysis of non-subtracted waveforms for standard and deviant sounds is illustrated in Fig. 3. The repeated-measures ANOVA included the within-subject factors of stimulus status (2 levels - standard; deviant), valence (3 levels), and ROI (4 levels). An enhanced negativity to deviant compared to standard vocalizations was observed for the three valence types [main effect of stimulus status $-F(1$, 22) $\left.=61.506, p<.001, \eta_{\mathrm{p}}^{2}=.737\right]$. Furthermore, a significant interaction between stimulus status and valence $[F(2$, $\left.44)=22.406, p<.001, \eta_{p}^{2}=.505\right]$ revealed less negative amplitude for happy relative to both neutral $(p=.004)$ and angry $(p=.004)$ standards, as well as more negative amplitude for happy relative to angry deviants $(p=.003)$, and for neutral relative to angry deviants $(p=.012)$.

\subsection{Effects of emotion on the Repetition Positivity}

Considering the frontocentral distribution of the Repetition Positivity (Baldeweg, 2007), the frontal (Fz, F3, F4) and frontocentral (FCz, FC3, FC4) ROIs were the target of the analysis. The Repetition Positivity amplitude was analyzed by a repeatedmeasures analysis of variance (ANOVA) with valence (neutral, happy [laughter], angry [growls]), number of repetitions (5 levels), and ROI as within-subject factors, in two latency windows (80-160 msec; 180-260 msec). We observed that the probabilistic properties of the stimulus sequence (i.e., the number of previous repetitions) yielded rapid and stimulus-specific adaptation of neural responses to the repeated vocal sounds (see Fig. 4 and Supplementary Fig. 1).

In the interval of $80-160 \mathrm{msec}$ (P50), a main effect of repetition $\left[F(4,88)=9.017, p<.001, \eta_{p}^{2}=.291\right]$ indicated a stepwise positivity increase as a function of the number of repetitions (block $1<$ block $3-p=.028$; block $1<$ block $4-$ $p=.014$; block $1<$ block $5-p=.033$ ). Furthermore, amplitude was generally more positive for both happy and neutral vocalizations compared to angry standards [main effect of valence $-F(2,44)=7.229, p=.002, \eta_{\mathrm{p}}^{2}=.247$; angry $<$ neutral $p=.039$; angry $<$ happy $-p=.002]$. Nonetheless, the interaction between valence and repetition number was not significant $(p>.05)$.

In the interval of $180-260 \mathrm{msec}(\mathrm{P} 2)$, a main effect of repetition number $\left[F(4,88)=8.600, p<.001, \eta_{p}^{2}=281\right]$ showed an overall stepwise increase in mean standard ERP amplitude with repetition (block $1<2-p=.065$; block $1<3-p=.05$, block $1<4-p=.026$, block $1<5-p=.037)$. These effects were dependent of valence. A significant interaction between repetition number, valence, and $\operatorname{ROI}[F(8,176)=3.139, p=.002$, $\left.\eta_{\mathrm{p}}^{2}=.125\right]$ revealed the following effects: whereas conditions did not differ in block 1 ( $10 \%$ of repetitions $-p>.05)$, in the second block ( $25 \%$ of repetitions), amplitude was increased for happy compared to angry standards only (frontal ROI $p=.042$; frontocentral ROI $-p=.022$ ). From blocks 3 (50\% of repetitions) to 5 (100\% of repetitions), amplitude increased significantly for happy compared to both angry and neutral standards (block 3: frontal ROI - happy $>$ neutral $-p=.005$, happy $>$ angry $-p<.001$; frontocentral ROI - happy $>$ neutral $-p=.006$, happy $>$ angry $-p=.001$; block 4: frontal ROI happy $>$ neutral $-p=.001$, happy $>$ angry $-p=.001$; frontocentral ROI - happy $>$ neutral $-p=.003$, happy $>$ angry $p=.003$; block 5: frontal ROI - happy $>$ neutral $-p=.002$, happy $>$ angry $-p=.001$; frontocentral ROI - happy $>$ neutral $-p=.003$, happy $>$ angry $-p=.001$ ). Importantly, repetition effects only reached significance in the case of laughter, at the frontocentral ROI (block $1<$ block $2-p=.017$; block $1<$ block 3 $-p=.007$, block $1<$ block $4-p=.029$; block $1<$ block $5-$ $p=.043)$.

\subsection{Effects of stimulus status and emotion on neural oscillations}

The within-subject factors of stimulus status, valence, and ROI were included in the repeated-measures ANOVA. Prestimulus beta power $(13-30 \mathrm{~Hz})$ was modulated by both valence and stimulus status [interaction effect $-F(2$, 44) $\left.=3.568, p=.037, \eta_{\mathrm{p}}^{2}=.140\right]$. The interaction was followed-

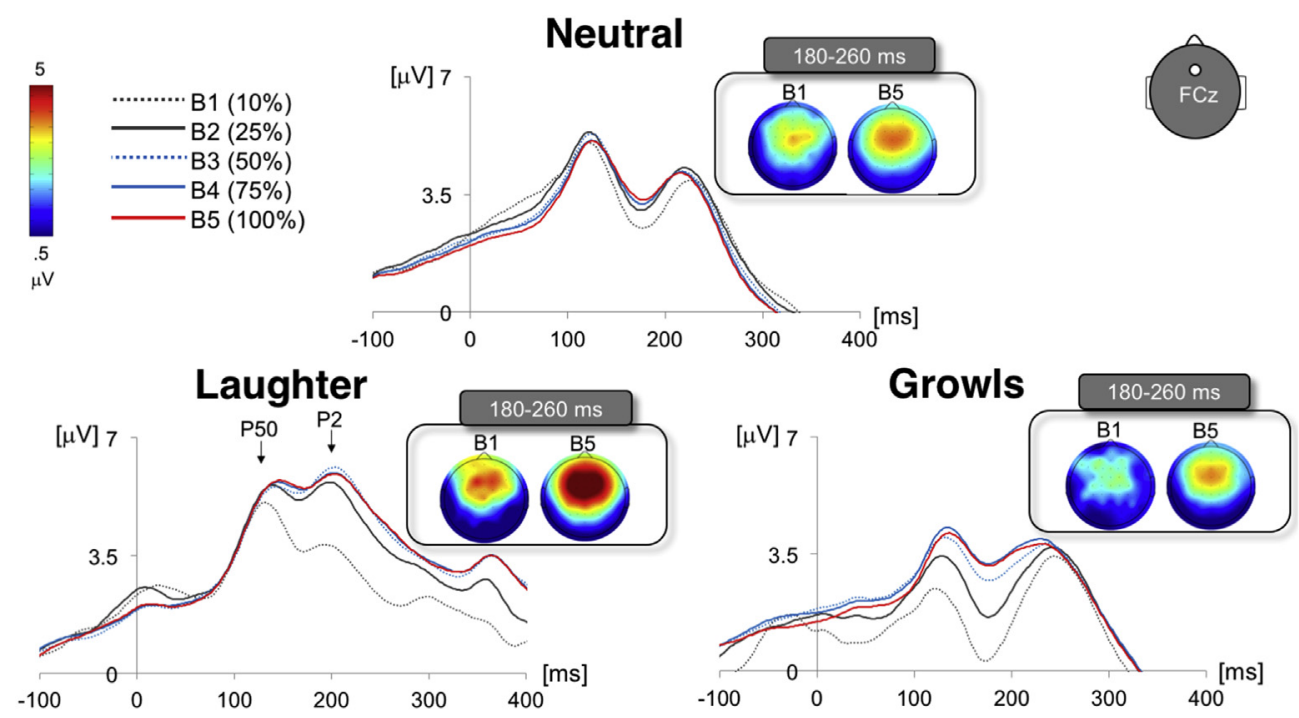

Fig. 4 - Repetition effects for standard vocalizations with neutral, positive (laughter), and negative (growls) valence. 
up by testing the effects of condition for standard and deviant sounds separately. In the case of standard sounds, beta power was increased for happy (laughter) relative to neutral and angry (growls) vocalizations [condition effect - $F(2$, $\left.44)=6.508, p=.003, \eta_{\mathrm{p}}^{2}=.228\right]$, even though the comparison was only statistically significant in the case of neutral vocalizations (happy us. neutral $-p=.005$; happy us. angry $p=.079)$. In the case of deviant sounds, beta power did not differ between conditions $(p>.05)$ (see Fig. 5).

\subsection{A relationship between oscillatory activity and ERP amplitude?}

The relationship between neural oscillations and ERPs was examined via a linear regression analysis. The mean power and ERP amplitude of standard sounds in the four ROIs were analyzed for each valence type separately. Pre-stimulus beta power predicted the Repetition Positivity (180-260 msec, 100\% repetitions) amplitude related to happy (laughter) $(B=104.269, t=2.348, p=.029)$, but not angry $(p>.05)$, standard vocalizations: the higher the power, the more positive the ERP amplitude for laughter.

\section{Discussion}

In a dynamically changing environment, the brain actively compares predictions about upcoming sensory events with stored sensory information to minimize prediction errors. In the current study, we probed how predictions of the emotional quality (valence) of vocalizations and actual sensory input are compared during pre-attentive voice processing. Our results revealed that the perceived significance of a vocalization alters the way the brain generates predictions about upcoming vocalizations in an unattended auditory sensory environment. On the one hand, the analysis of neural activity elicited by standard (frequent) vocalizations indicated enhanced top-down expectations for laughter, reflected in enhanced pre-stimulus beta power and an increased Repetition Positivity. On the other hand, the EEG response to deviant vocalizations demonstrated that violating probability-based expectancies elicited stronger error signals in the case of laughs compared to growls and neutral vocal stimuli.

\subsection{Emotional vocal change detection in ERPs}

Even though the three types of vocalizations elicited a MMN, vocal change was treated differently as a function of stimulus valence: MMN peaked earlier and was more negative for laughter relative to both growls and neutral vocalizations. In other words, a prediction error was enhanced by the processing of vocal sounds with a positive emotional quality.

In experimental setups aiming to elicit a MMN, short-term predictive representations of regularities are formed based on the probability of events that are often repeated (standards). These representations guide the automatic detection of rare events (deviants) that do not match the predictions. Similarly, in the current experiment the auditory system has to extract high-level features of the vocalizations to generate a deviance response, such as their emotional valence. Therefore, adding

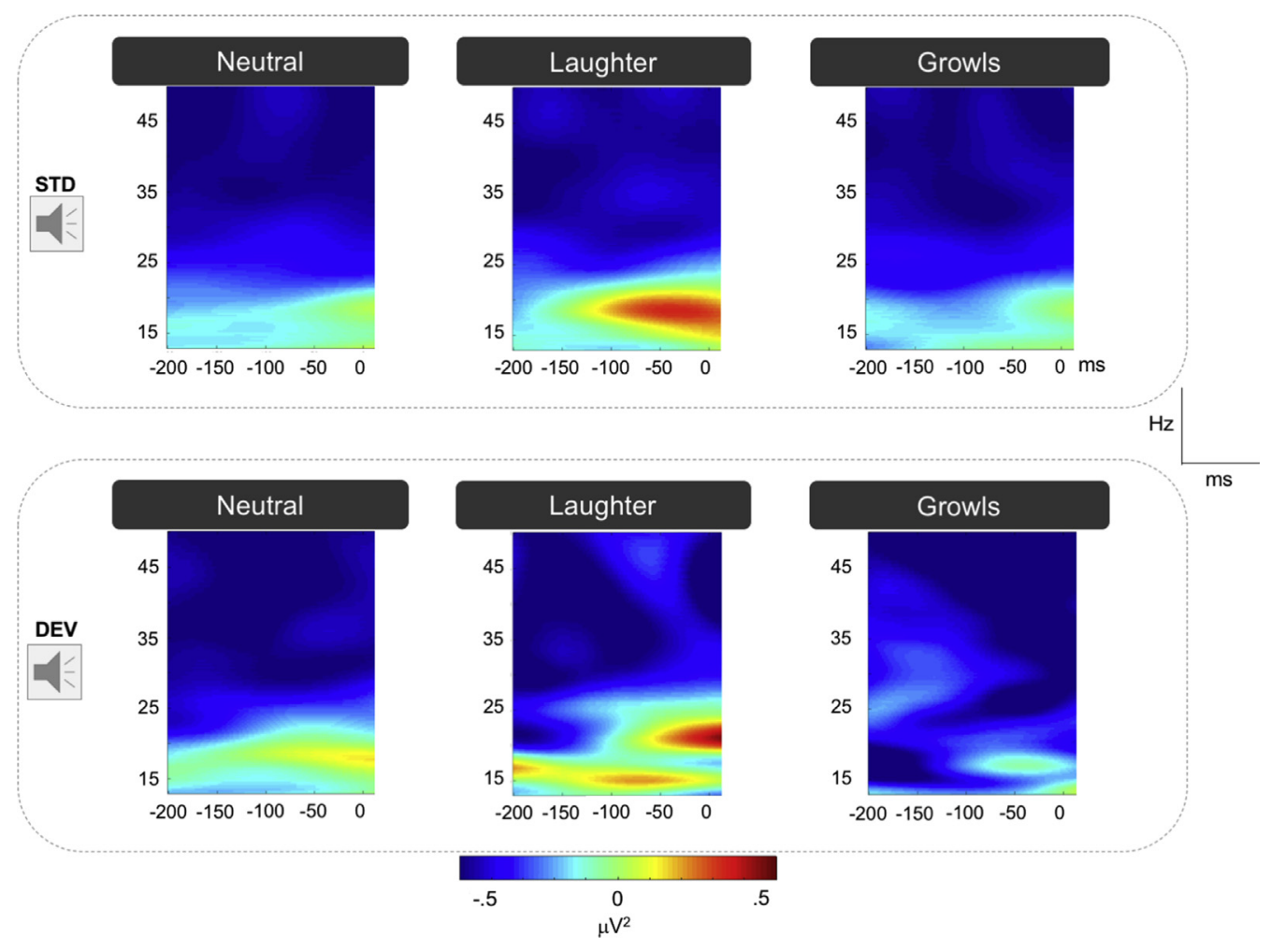

Fig. 5 - Time-frequency maps of pre-stimulus induced power at electrode $\mathbf{C z}$ for standard vocalizations with neutral, positive (laughter), and negative (growls) valence. 
to previous evidence on emotional words or pseudowords (e.g., Schirmer et al., 2005), the observed valence effects in the MMN response suggest that emotional information conveyed by short affective bursts may be decoded, at least in part, in a preattentive way (Leitman et al., 2011; Schirmer et al., 2005). An important question is whether the mismatch response arises as a consequence of the emotional quality of the stimulus or the physical differences between the vocalizations. As we controlled for the effects of physical differences between vocalizations computing difference waveforms based on a like-to-like subtraction procedure, it seems unlikely that the observed difference between laughter and growls can be attributed to the acoustic properties of the vocalizations. Furthermore, as arousal ratings did not differ between happy and angry vocalizations, the observed MMN differences indicate that valence played the most critical role in modulating prediction.

Increased MMN amplitude for happy (laughter) vocalizations is at odds with previous visual MMN studies that reported a negativity bias (e.g., Kimura, Kondo, Ohira, \& Schröger, 2012; Stefanics, Csukly, Komlósi, Czobor, \& Czigler, 2012). The increased negativity for stimuli of positive valence may signal the hedonic value tagging of a vocal signal. Similarly, a previous fMRI study found that vocal expressions of happiness preferentially engaged regions of the temporal cortex and inferior frontal gyrus (regions that are considered to be generators of the auditory MMN-e.g., Alho, 1995), when contrasted with anger (Johnstone et al., 2006). This pattern of brain activation was interpreted as reflecting the particularly high salience of affiliative social vocal cues. Compared to threat-related vocal cues (i.e., anger), positive vocal signals, such as laughter, are prevalent stimuli in daily social interactions of individuals with no mood disorders (e.g., Scott et al., 2014). The distinctiveness of positive vocalizations or laughter has also been pointed out in previous electrophysiological studies that reported an earlier MMN latency for happy pseudowords (Schirmer et al., 2005), or an earlier P2 for laughter expressions (Pell et al., 2015). Due to their relevance in social interactions, such as in social bonding, laughter may represent a particularly relevant social signal (Johnstone et al., 2006; Scott et al., 2014), which has also been associated with the elicitation of positive affect or emotional contagion (e.g., Pell et al., 2015). The effects of valence on the MMN amplitude and latency may thus indicate an experience-based modulatory effect on predictive processing of vocal expressions of positive emotion.

EEG activity related to standard vs. deviant sounds sheds light on different neural processes (e.g., Garrido et al., 2009): ERP activity related to the standard sounds informs on how predictions are formed based on regularities in the auditory environment; deviant-related activity clarifies the precision with which changes in the environment are represented (Todd et al., 2012). We observed that the Repetition Positivity was enhanced for laughter. The higher the number of repetitions, the more enhanced the representation of the standard and the stronger the prediction for this vocal emotion were. The systematic changes in ERP amplitude as a function of an increase in the number of standard stimulus repetitions is compatible with the hypothesis that a prediction error is minimized and with a relay of predictive information via top- down mechanisms (Baldeweg, 2007). Specifically, they suggest enhanced top-down predictive signals for stimuli of positive valence. Simultaneously, violating expectancies involving predictable (standard) neutral information yielded stronger error signals when the unpredicted (deviant) stimulus was of positive valence than of negative valence. The size of the deviant negativity suggests that context-sensitive predictions about the auditory environment (Todd et al., 2012) were facilitated for positive vocalizations. That laughs evoked both increased Repetition Positivity and Mismatch Negativity responses is in good agreement with the observation that more persistent traces result in larger Repetition Positivity and enhanced MMN with shorter onset latency (Baldeweg, 2007). To confirm that positive valence enhances the repetition effects at a neuronal scale, further research using other types of positive sounds (e.g., triumph, sensual pleasure) should prove informative.

Note that an unexpected finding was the lack of MMN differences between angry and neutral vocalizations. Despite the similar MMN amplitude, the examination of ERP activity separately for standard and deviant sounds supported the differential processing of neutral sounds and growls. Indeed, the deviant negativity was enhanced for neutral compared to angry sounds. Further, a closer look at the differences in the ERP amplitude between standard and deviant stimuli for each valence type revealed a smaller difference in the case of angry vocalizations only (see Table 3: Neutral $=-2.18 \mu \mathrm{V}$; Laughter $=-2.94 \mu \mathrm{V}$; Growls $=-1.43 \mu \mathrm{V}$ ) suggesting that growls were less sensitive to the probability of stimulus presentation. A related possibility is that predictive processes are impaired for stimuli with negative valence (for a similar finding in a language processing task, see Pinheiro, del Re, Nestor, et al., 2013). This hypothesis is further supported by the observation that the standard positivity was not modulated by the number of

Table 3 - Mean amplitude $(\mu \mathrm{V})$ of the MMN and repetition positivity for each condition.

\begin{tabular}{llll}
\hline & \multicolumn{3}{c}{ Condition } \\
\cline { 2 - 4 } & Neutral & $\begin{array}{c}\text { Happy } \\
\text { (Laughter) }\end{array}$ & $\begin{array}{c}\text { Angry } \\
\text { (Growls) }\end{array}$ \\
\hline Mismatch Negativity & & & \\
Standard & $.71(.20)$ & $1.20(.16)$ & $.49(.28)$ \\
Deviant & $-1.43(.31)$ & $-1.74(.21)$ & $-.94(.27)$ \\
Difference & -2.18 & -2.94 & -1.43 \\
$\quad$ (Deviant-Standard) & & & \\
Repetition Positivity (P50: $80-160 \mathrm{msec})$ & & \\
$10 \%$ & $3.73(.63)$ & $4.26(.68)$ & $1.67(.69)$ \\
$25 \%$ & $4.02(.42)$ & $4.60(.59)$ & $2.58(.49)$ \\
$50 \%$ & $4.15(.39)$ & $4.59(.43)$ & $3.21(.38)$ \\
$75 \%$ & $4.10(.38)$ & $4.77(.41)$ & $3.43(.38)$ \\
$100 \%$ & $4.16(.35)$ & $4.78(.39)$ & $3.29(.37)$ \\
Repetition Positivity (P2: $180-260 \mathrm{msec})$ & & \\
$10 \%$ & $2.87(.62)$ & $3.50(.70)$ & $1.99(.75)$ \\
$25 \%$ & $3.27(.30)$ & $4.74(.65)$ & $2.54(.53)$ \\
$50 \%$ & $3.42(.28)$ & $5.16(.41)$ & $3.06(.35)$ \\
$75 \%$ & $3.41(.29)$ & $5.10(.38)$ & $3.37(.35)$ \\
$100 \%$ & $3.47(.28)$ & $5.11(.37)$ & $3.28(.33)$ \\
\hline
\end{tabular}

Note: Standard Error is shown in parentheses; the mean values reflect the average of amplitude across the ROIs included in the statistical analyses. 
repetitions in the case of growls. The disruptive effects of negative valence on prediction may have resulted in a MMN pattern similar to the MMN elicited by neutral sounds. However, this hypothesis requires further investigation.

\subsection{Emotional vocal change detection in neural oscillations}

The second main goal of our study was to investigate whether emotional valence effects related to vocal change detection are also reflected in brain oscillatory activity. The analysis of neural oscillations aimed to provide further insights into predictive processes associated with vocal emotional perception, which could not be obtained by the ERP technique alone. We found valence-specific involvement of beta activity in the prediction of vocal emotions.

The idea that beta oscillations are involved in emotional processes is not new (e.g., Ray \& Cole, 1985). Emotion effects in the oscillatory activity in the beta frequency band have been reported in studies employing dynamic stimuli such as audiovisual stimuli (Jessen \& Kotz, 2011; Jessen et al., 2012), or prosody (e.g., Chen etal., 2015). In particular, beta oscillations were found to be particularly sensitive to the reward/hedonic value of the cues (reflected in power increases-Doñamayor, Schoenfeld, \& Munte, 2012) us. their aversive content (reflected in power decreases-e.g., DeLaRosa et al., 2014). Specifically, our findings underscore the role of pre-stimulus activity for incoming sensations and vocal change detection: pre-stimulus beta power was increased for happy compared to angry and neutral standard vocalizations. This finding supports the modulatory role of pre-stimulus brain states on subsequent perception (e.g., Keil, Muller, Hartmann, \& Weisz, 2014), and the significance of beta activity in the prediction of both time and content of upcoming stimuli (e.g., Arnal, 2012; Chang, Bosnyak, \& Trainor, 2016; Geerligs \& Akyürek, 2012; Weiss \& Mueller, 2012). Previous studies suggested that beta oscillations adapt to a changing environment: beta power is increased when the current cognitive state is to be maintained (Engel \& Fries, 2010), while it is decreased when an action is necessary or the current neurocognitive network configuration needs to be revised or changed (e.g., Lewis, Wang, \& Bastiaansen, 2015). The increased beta power before stimulus onset for expressions of laughter may signal enhanced top-down expectations for positive vocalizations. This hypothesis is further strengthened by the observation that internal models (predictions) shaped the neural response to the vocalizations and led to an increase of the signal-to-noise ratio for the predicted vocal signal (i.e., linear increase in the positive amplitude of the evoked neural response based on number of repetitions) and consequently facilitating its processing. Of note, pre-stimulus beta power predicted the size of the standard-related positivity to happy vocalizations, indicating that top-down expectations occurring before stimulus onset modulate the responsiveness to the forthcoming (predicted) stimulus.

As beta oscillations have been related to the activation of sensorimotor processes, the current findings may further indicate the involvement of the sensorimotor system in vocal emotional perception and comprehension (e.g., action simulation in motor regions), even when attention is not directed toward the vocalization (e.g., Banissy et al., 2010; Jabbi et al.,
2015). This is not surprising as the voice represents a direct product of body movements (e.g., Jessen et al., 2012), and as perception is intricately linked to action (e.g., Scott, Sauter, \& McGettigan, 2009). In particular, the preferential activation of the motor system (i.e., automatic preparation of responsive orofacial gestures) in response to positive vocal emotions, such as amusement and triumph (compared to negative vocal expressions such as disgust and fear) was proposed to play a fundamental role in the formation of empathic responses (i.e., mirroring the positive emotional states of others), and in the establishment of cohesive social bonds (Warren et al., 2006). However, in the absence of source localization of the beta effects, this hypothesis remains speculative. Questions to be addressed in future studies thus include the role of sensorimotor processes in vocal emotional change detection.

\subsection{Implications for current models of vocal emotional perception and clinical conditions}

So how is an emotional (positive vs. negative valence) change in the voice detected when we do not focus attention to it? Our findings add to previous studies indicating that emotional voice processing is at least partially automatic (e.g., Liu et al., 2012; Schirmer et al., 2005), and point to a rapid categorization of emotionally relevant acoustic vocal properties that were not attended to (e.g., Goydke, Altenmüller, Möller, \& Münte, 2004; Schirmer et al., 2005; Thonnessen et al., 2010). In addition, they align with accumulating evidence showing that rapid emotional salience detection happens within the first $200 \mathrm{msec}$ after voice onset (linked to the fronto-centrally distributed P2 component in studies of explicit vocal emotional processing e.g., Paulmann \& Kotz, 2008; Pinheiro et al., 2013), and that discrete emotional categories may be distinguished from one another and from neutral sounds within these first $200 \mathrm{msec}$ (e.g., Liu et al., 2012; Pinheiro et al., 2013, 2014). Even though stimulus probability was kept the same for all conditions, an enhanced MMN and Repetition Positivity amplitude, as well as enhanced induced beta power for positive vocalizations revealed stronger predictions for laughter. Together, these findings suggest the existence of specialized brain mechanisms for emotional change detection within low-level auditory cortical regions (Thonnessen et al., 2010). Even though previous studies did not find valence-specific differences in amplitude within the first $200 \mathrm{msec}$ after voice onset, differences in the type of stimulus may have accounted for the lack of specific valence effects. Indeed, these previous studies relied on prosody, and more recent studies suggest that emotional prosody elicit later and less differentiated ERP responses than prosodic speech during early emotion evaluation (Pell et al., 2015).

Alterations in predictive processes, such as aberrant encoding of prediction errors, have been related to the formation of symptoms such as hallucinations and delusions (e.g., Fletcher \& Frith, 2009). Deficits in MMN amplitude have been consistently reported in schizophrenia patients (e.g., Todd et al., 2008, 2012), and contribute to poor psychosocial outcome in schizophrenia (Light, Swerdlow, \& Braff, 2007). Deficits in vocal emotional perception are also a central feature of schizophrenia (e.g., Pinheiro et al., 2013, 2014). Thus, probing the MMN with vocal emotions may provide a promising tool to study predictive coding related to social 
communication processes, and its abnormalities in disorders such as psychosis.

\section{Conclusions}

Communicating and comprehending vocal emotions is a highly complex process. As the brain starts different operations when processing complex vocal information, these operations may be better understood in a multi-measures approach including ERPs, neural oscillations, and behavioral data. In the current study, we explored the effects of valence on predictive mechanisms during vocal emotional perception. We showed that stimulus valence modulates prediction and change detection during implicit vocal emotional perception. The MMN response was increased to happy (laughter) compared to neutral and angry (growls) vocalizations. Laughter also elicited an increased Repetition Positivity as a function of the number of standard repetitions. Furthermore, beta power was enhanced for laughter in the $150 \mathrm{msec}$ before stimulus onset and predicted the Repetition Positivity for standards.

These findings confirm that the brain is tuned to predict emotional cues and to detect vocal changes as a function of stimulus valence and social significance. Specifically, they suggest that the ability to predict future events based on what we have heard before is enhanced when these events have a positive quality. In other words, compared to growls, laughter seems to be a better change detector of the human voice.

\section{Acknowledgments}

The authors gratefully acknowledge all the participants who collaborated in the study, and particularly Marcelo Dias for his help with data acquisition, and Andréia Rauber for her critical help in editing the sound files.

This work was supported by Grants IF/00334/2012, PTDC/ PSI-PCL/116626/2010, PTDC/MHN-PCN/3606/2012, and PTDC/ MHC-PCN/0101/2014 funded by the Science and Technology Foundation (Fundação para a Ciência e a Tecnologia - FCT, Portugal) and FEDER (European Regional Development Fund) through the European programs QREN (National Strategic Reference Framework), and COMPETE (Operational Programme 'Thematic Factors of Competitiveness'), awarded to A.P.P (IF/ 00334/2012, PTDC/PSI-PCL/116626/2010, PTDC/MHN-PCN/ 3606/2012, PTDC/MHC-PCN/0101/2014) and S.A.K. (PTDC/ MHN-PCN/3606/2012, PTDC/MHC-PCN/0101/2014).

\section{Supplementary data}

Supplementary data related to this article can be found at http://dx.doi.org/10.1016/j.cortex.2017.03.018.

\section{R E F E R E N C E S}

Alho, K. (1995). Cerebral generators of mismatch negativity $(\mathrm{MMN})$ and its magnetic counterpart (MMNm) elicited by sound changes. Ear and Hearing, 16(1), 38-51. http://doi.org/10. 1097/00003446-199502000-00004.

Arnal, L. H. (2012). Predicting "when" using the motor system's beta-band oscillations. Frontiers in Human Neuroscience, 6, 225. http://doi.org/10.3389/fnhum.2012.00225.

Arnal, L. H., \& Giraud, A. L. (2012). Cortical oscillations and sensory predictions. Trends in Cognitive Sciences, 16(7), 390-398. http://doi.org/10.1016/j.tics.2012.05.003.

Balconi, M., \& Mazza, G. (2009). Brain oscillations and BIS/BAS (behavioral inhibition/activation system) effects on processing masked emotional cues. ERS/ERD and coherence measures of alpha band. International Journal of Psychophysiology, 74(2), 158-165. http://doi.org/10.1016/j.ijpsycho.2009.08.006.

Baldeweg, T. (2007). ERP repetition effects and mismatch negativity generation: A predictive coding perspective. Journal of Psychophysiology, 21(3-4), 204-213. http://doi.org/10.1027/ 0269-8803.21.34.204.

Banissy, M. J., Sauter, D. A., Ward, J., Warren, J. E., Walsh, V., \& Scott, S. K. (2010). Suppressing sensorimotor activity modulates the discrimination of auditory emotions but not speaker identity. The Journal of Neuroscience, 30(41), 13552-13557. http://doi.org/10.1523/JNEUROSCI.0786-10.2010.

Bastiaansen, M. C. M., Magyari, L., \& Hagoort, P. (2010). Syntactic unification operations are reflected in oscillatory dynamics during on-line sentence comprehension. Journal of Cognitive Neuroscience, 22(7), 1333-1347. http://dx.doi.org/10.1162/ jocn.2009.21283.

Belin, P., Bestelmeyer, P. E. G., Latinus, M., \& Watson, R. (2011). Understanding voice perception. British Journal of Psychology, 102(4), 711-725. http://doi.org/10.1111/j.2044-8295.2011.02041.x.

Belin, P., Fecteau, S., \& Bedard, C. (2004). Thinking the voice: Neural correlates of voice perception. Trends in Cognitive Sciences, 8(3), 129-135. http://doi.org/10.1016/j.tics.2004.01.008.

Belin, P., Fillion-Bilodeau, S., \& Gosselin, F. (2008). The Montreal affective voices: A validated set of nonverbal affect bursts for research on auditory affective processing. Behavior Research Methods, 40(2), 531-539. http://doi.org/10.3758/BRM.40.2.531.

Bernasconi, F., Manuel, A. L., Murray, M. M., \& Spierer, L. (2011). Pre-stimulus beta oscillations within left posterior sylvian regions impact auditory temporal order judgment accuracy. International Journal of Psychophysiology, 79(2), 244-248. http:// doi.org/10.1016/j.ijpsycho.2010.10.017.

Boersma, P., \& Weenink, D. (2013). Praat: Doing phonetics by computer [Computer program]. Version 5.3.53. Retrieved from http://www.praat.org/.

Bradley, M. M., \& Lang, P. J. (1994). Measuring emotion: The selfassessment manikin and the semantic differential. Journal of Behavior Therapy and Experimental Psychiatry, 25(1), 49-59. http://dx.doi.org/10.1016/0005-7916(94)90063-9.

Bradley, M. M., \& Lang, P. J. (2000). Affective reactions to acoustic stimuli. Psychophysiology, 37(2), 204-215. http://doi.org/10. 1111/1469-8986.3720204.

Canavarro, M. C. (1999). Inventário de Sintomas Psicopatológicos [Brief Symptoms Inventory]: BSI. In L. S. A. M. R. Simões, \& M. Gonçalves (Eds.), Psychological Tests in Portugal: vol. II. Testes e provas psicológicas em Portugal. Braga: SHO/APPORT.

Chandrasekaran, B., Krishnan, A., \& Gandour, J. T. (2007). Mismatch negativity to pitch contours is influenced by language experience. Brain Research, 1128(1), 148-156. http:// doi.org/10.1016/j.brainres.2006.10.064.

Chang, A., Bosnyak, D. J., \& Trainor, L. J. (2016). Unpredicted pitch modulates beta oscillatory power during rhythmic entrainment to a tone sequence. Frontiers in Psychology, 7, 327. http://doi.org/10.3389/fpsyg.2016.00327.

Chen, C., Lee, Y.-H., \& Cheng, Y. (2014). Anterior insular cortex activity to emotional salience of voices in a passive oddball paradigm. Frontiers in Human Neuroscience, 8, 743. http://doi. org/10.3389/fnhum.2014.00743. 
Chen, X., Pan, Z., Wang, P., Zhang, L., \& Yuan, J. (2015). EEG oscillations reflect task effects for the change detection in vocal emotion. Cognitive Neurodynamics, 9(3), 351-358. http:// doi.org/10.1007/s11571-014-9326-9.

Cohen, M. X. (2016). Rigor and replication in time-frequency analyses of cognitive electrophysiology data. International Journal of Psychophysiology, 1-8. http://doi.org/10.1016/j. ijpsycho.2016.02.001.

Costa-Faidella, J., Baldeweg, T., Grimm, S., \& Escera, C. (2011). Interactions between "what" and "when" in the auditory system: Temporal predictability enhances repetition suppression. The Journal of Neuroscience: The Official Journal of the Society for Neuroscience, 31(50), 18590-18597. http://doi.org/ 10.1523/JNEUROSCI.2599-11.2011.

Deiber, M.-P., Missonnier, P., Bertrand, O., Gold, G., FazioCosta, L., Ibañez, V., et al. (2007). Distinction between perceptual and attentional processing in working memory tasks: A study of phase-locked and induced oscillatory brain dynamics. Journal of Cognitive Neuroscience, 19, 158-172. http:// doi.org/10.1162/jocn.2007.19.1.158.

DeLaRosa, B. L., Spence, J. S., Shakal, S. K. M., Motes, M. A., Calley, C. S., Calley, V. I., ... Kraut, M. A. (2014). Electrophysiological spatiotemporal dynamics during implicit visual threat processing. Brain and Cognition, 91, 54-61. http:// doi.org/10.1016/j.bandc.2014.08.003.

Delorme, A., \& Makeig, S. (2004). EEGLAB: An open source toolbox for analysis of single-trial EEG dynamics including independent component analysis. Journal of Neuroscience Methods, 134(1), 9-21. http://doi.org/10.1016/j.jneumeth.2003. 10.009.

Doñamayor, N., Schoenfeld, M. A., \& Munte, T. F. (2012). Magnetoand electroencephalographic manifestations of reward anticipation and delivery. NeuroImage, 62(1), 17-29. http://doi. org/10.1016/j.neuroimage.2012.04.038.

Engel, A. K., \& Fries, P. (2010). Beta-band oscillations-signalling the status quo? Current Opinion in Neurobiology, 20(2), 156-165. http://doi.org/10.1016/j.conb.2010.02.015.

Fletcher, P. C., \& Frith, C. D. (2009). Perceiving is believing: A Bayesian approach to explaining the positive symptoms of schizophrenia. Nature Reviews Neuroscience, 10(1), 48-58. http://doi.org/10.1038/nrn2536.

Friston, K. (2012). Prediction, perception and agency. International Journal of Psychophysiology, 83(2), 248-252. http://doi.org/10. 1016/j.ijpsycho.2011.11.014.

Garrido, M. I., Kilner, J. M., Stephan, K. E., \& Friston, K. J. (2009). The mismatch negativity: A review of underlying mechanisms. Clinical Neurophysiology, 120(3), 453-463. http:// doi.org/10.1016/j.clinph.2008.11.029.

Geerligs, L., \& Akyürek, E. G. (2012). Temporal integration depends on increased prestimulus beta band power. Psychophysiology, 49(11), 1632-1635. http://doi.org/10.1111/j.1469-8986.2012.01453.x.

Goydke, K. N., Altenmüller, E., Möller, J., \& Münte, T. F. (2004). Changes in emotional tone and instrumental timbre are reflected by the mismatch negativity. Cognitive Brain Research, 21(3), 351-359. http://doi.org/10.1016/j.cogbrainres.2004.06.009.

Güntekin, B., \& Başar, E. (2010). Event-related beta oscillations are affected by emotional eliciting stimuli. Neuroscience Letters, 483(3), 173-178. http://doi.org/10.1016/j.neulet.2010.08.002.

Haenschel, C., Vernon, D. J., Dwivedi, P., Gruzelier, J. H., \& Baldeweg, T. (2005). Event-related brain potential correlates of human auditory sensory memory-trace formation. The Journal of Neuroscience, 25(45), 10494-10501. http://doi.org/10.1523/ jneurosci.1227-05.2005.

Hanslmayr, S., Aslan, A., Staudigl, T., Klimesch, W., Herrmann, C. S., \& Bäuml, K. H. (2007). Prestimulus oscillations predict visual perception performance between and within subjects. NeuroImage, 37(4), 1465-1473. http://doi. org/10.1016/j.neuroimage.2007.07.011.
Hawk, S. T., van Kleef, G. a, Fischer, A. H., \& van der Schalk, J. (2009). "Worth a thousand words": Absolute and relative decoding of nonlinguistic affect vocalizations. Emotion, 9(3), 293-305. http://doi.org/10.1037/a0015178.

Hipp, J. F., \& Siegel, M. (2013). Dissociating neuronal gamma-band activity from cranial and ocular muscle activity in EEG. Frontiers in Human Neuroscience, 7, 338. http://doi.org/10.3389/ fnhum.2013.00338.

Jabbi, M., Kohn, P. D., Nash, T., Ianni, A., Coutlee, C., Holroyd, T., ... Berman, K. F. (2015). Convergent BOLD and beta-band activity in superior temporal sulcus and frontolimbic circuitry underpins human emotion cognition. Cerebral Cortex, 25(7), 1878-1888. http://doi.org/10.1093/cercor/ bht427.

Jacobsen, T., \& Schröger, E. (2003). Measuring duration mismatch negativity. Clinical Neurophysiology, 114(6), 1133-1143. http:// dx.doi.org/10.1016/S1388-2457(03)00043-9.

Jessen, S., \& Kotz, S. A. (2011). The temporal dynamics of processing emotions from vocal, facial, and bodily expressions. NeuroImage, 58(2), 665-674. http://doi.org/10. 1016/j.neuroimage.2011.06.035.

Jessen, S., Obleser, J., \& Kotz, S. A. (2012). How bodies and voices interact in early emotion perception. PLoS One, 7(4), e36070. http://doi.org/10.1371/journal.pone.0036070.

Johnstone, T., van Reekum, C. M., Oakes, T. R., \& Davidson, R. J. (2006). The voice of emotion: An FMRI study of neural responses to angry and happy vocal expressions. Social Cognitive and Affective Neuroscience, 1(3), 242-249. http://doi. org/10.1093/scan/nsl027.

Keil, A., Müller, M. M., Gruber, T., Wienbruch, C., Stolarova, M., \& Elbert, T. (2001). Effects of emotional arousal in the cerebral hemispheres: A study of oscillatory brain activity and eventrelated potentials. Clinical Neurophysiology, 112(11), 2057-2068. http://dx.doi.org/10.1016/S1388-2457(01)00654-X.

Keil, J., Muller, N., Hartmann, T., \& Weisz, N. (2014). Prestimulus beta power and phase synchrony influence the sound-induced flash illusion. Cerebral Cortex, 24(5), 1278-1288. http://doi.org/ 10.1093/cercor/bhs409.

Keren, A. S., Yuval-Greenberg, S., \& Deouell, L. Y. (2010). Saccadic spike potentials in gamma-band EEG: Characterization, detection and suppression. NeuroImage, 49(3), 2248-2263. http://doi.org/10.1016/j.neuroimage.2009.10.057.

Kim, J. S., \& Chung, C. K. (2008). Language lateralization using MEG beta frequency desynchronization during auditory oddball stimulation with one-syllable words. NeuroImage, 42(4), 1499-1507. http://doi.org/10.1016/j.neuroimage.2008.06.001.

Kimura, M., Kondo, H., Ohira, H., \& Schröger, E. (2012). Unintentional temporal context-based prediction of emotional faces: An electrophysiological study. Cerebral Cortex, 22(8), 1774-1785. http://doi.org/10.1093/cercor/bhr244.

Kotchoubey, B., Kaiser, J., Bostanov, V., Lutzenberger, W., \& Birbaumer, N. (2009). Recognition of affective prosody in brain-damaged patients and healthy controls: A neurophysiological study using EEG and whole-head MEG. Cognitive, Affective \& Behavioral Neuroscience, 9(2), 153-167. http://doi.org/10.3758/CABN.9.2.153.

Kriegeskorte, N., Simmons, W. K., Bellgowan, P. S. F., \& Baker, C. I. (2009). Circular analysis in systems neuroscience: The dangers of double dipping. Nature Neuroscience, 12(5), 535-540. http:// doi.org/10.1167/8.6.88.

Lange, J., Halacz, J., Van Dijk, H., Kahlbrock, N., \& Schnitzler, A. (2012). Fluctuations of prestimulus oscillatory power predict subjective perception of tactile simultaneity. Cerebral Cortex, 22(11), 2564-2574. http://doi.org/10.1093/cercor/bhr329.

Laukka, P., Elfenbein, H. A., Soder, N., Nordstrom, H., Althoff, J., Chui, W., ... Thingujam, N. S. (2013). Cross-cultural decoding of positive and negative non-linguistic emotion vocalizations cross-cultural decoding of positive and negative non-linguistic 
emotion vocalizations. Frontiers in Psychology, 4, 353. http://doi. org/10.3389/fpsyg.2013.00353.

Leitman, D. I., Sehatpour, P., Garidis, C., Gomez-Ramirez, M., \& Javitt, D. C. (2011). Preliminary evidence of pre-attentive distinctions of frequency-modulated tones that convey affect. Frontiers in Human Neuroscience, 5(96), 1-8. http://doi.org/10. 3389/fnhum.2011.00096.

Lewis, A. G., Wang, L., \& Bastiaansen, M. (2015). Fast oscillatory dynamics during language comprehension: Unification versus maintenance and prediction? Brain and Language, 148, 51-63. http://doi.org/10.1016/j.bandl.2015.01.003.

Light, G. A., Swerdlow, N. R., \& Braff, D. L. (2007). Preattentive sensory processing as indexed by the MMN and P3a brain responses is associated with cognitive and psychosocial functioning in healthy adults. Journal of Cognitive Neuroscience, 19(10), 1624-1632. http://doi.org/10.1162/jocn. 2007.19.10.1624.

Liu, T., Pinheiro, A. P., Deng, G., Nestor, P. G., McCarley, R. W., \& Niznikiewicz, M. A. (2012). Electrophysiological insights into processing nonverbal emotional vocalizations. NeuroReport, 23(2), 108-112. http://doi.org/10.1097/WNR.0b013e32834ea757.

Müller, M. M., Keil, A., Gruber, T., \& Elbert, T. (1999). Processing of affective pictures modulates right-hemispheric gamma band EEG activity. Clinical Neurophysiology, 110(11), 1913-1920. http://dx.doi.org/10.1016/S1388-2457(99)00151-0.

Näätänen, R. (1995). The mismatch negativity: A powerful tool for cognitive neuroscience. Ear and Hearing, 16(1), 6-18.

Näätänen, R. (2001). The perception of speech sounds by the human brain as reflected by the mismatch negativity (MMN) and its magnetic equivalent (MMNm). Psychophysiology, 38(1), 1-21. http://doi.org/10.1111/1469-8986.3810001.

Nittono, H. (2006). Voluntary stimulus production enhances deviance processing in the brain. International Journal of Psychophysiology, 59(1), 15-21. http://doi.org/10.1016/j. ijpsycho.2005.06.008.

Oldfield, R. C. (1971). The assessment and analysis of handedness: The Edinburgh inventory. Neuropsychologia, 9(1), 97-113. http://dx.doi.org/10.1016/0028-3932(71)90067-4.

Omigie, D., Dellacherie, D., Hasboun, D., George, N., Clement, S., Baulac, M.,... Samson, S. (2015). An intracranial EEG study of the neural dynamics of musical valence processing. Cerebral Cortex, 25(11), 4038-4047. http://doi.org/10.1093/cercor/bhu118.

Paulmann, S., \& Kotz, S. A. (2008). Early emotional prosody perception based on different speaker voices. NeuroReport, 19(2), 209-213. http://doi.org/10.1097/WNR.0b013e3282f454db.

Paulmann, S., Seifert, S., \& Kotz, S. A. (2010). Orbito-frontal lesions cause impairment during late but not early emotional prosodic processing. Social Neuroscience, 5(1), 59-75. http://doi. org/10.1080/17470910903135668.

Pell, M. D., Rothermich, K., Liu, P., Paulmann, S., Sethi, S., \& Rigoulot, S. (2015). Preferential decoding of emotion from human non-linguistic vocalizations versus speech prosody. Biological Psychology, 111, 14-25. http://doi.org/10.1016/j. biopsycho.2015.08.008.

Pinheiro, A. P., del Re, E., Mezin, J., Nestor, P. G., Rauber, A., McCarley, R. W., ... Niznikiewicz, M. A. (2013a). Sensory-based and higher-order operations contribute to abnormal emotional prosody processing in schizophrenia: An electrophysiological investigation. Psychological Medicine, 43(3), 603-618. http://doi.org/10.1017/S003329171200133X.

Pinheiro, A. P., del Re, E., Nestor, P. G., McCarley, R. W., Gonçalves, O. F., \& Niznikiewicz, M. (2013b). Interactions between mood and the structure of semantic memory: Eventrelated potentials evidence. Social Cognitive and Affective Neuroscience, 8(5), 579-594. http://doi.org/10.1093/scan/nss035.

Pinheiro, A. P., Rezaii, N., Rauber, A., Liu, T., Nestor, P. G., McCarley, R. W., ... Niznikiewicz, M. A. (2014). Abnormalities in the processing of emotional prosody from single words in schizophrenia. Schizophrenia Research, 152(1), 235-241. http:// doi.org/10.1016/j.schres.2013.10.042.

Ray, W. J., \& Cole, H. W. (1985). EEG alpha activity reflects attentional demands, and beta activity reflects emotional and cognitive processes. Science, 228(4700), 750-752. http://doi.org/ 10.1126/science.3992243.

Roach, B. J., \& Mathalon, D. H. (2008). Event-related EEG timefrequency analysis: An overview of measures and an analysis of early gamma band phase locking in schizophrenia. Schizophrenia Bulletin, 34(5), 907-926. http://doi.org/10.1093/ schbul/sbn093.

Sammler, D., Grigutsch, M., Fritz, T., \& Koelsch, S. (2007). Music and emotion: Electrophysiological correlates of the processing of pleasant and unpleasant music. Psychophysiology, 44(2), 293-304. http://doi.org/10.1111/j.1469-8986.2007.00497.x.

Sauter, D. A., \& Eimer, M. (2010). Rapid detection of emotion from human vocalizations. Journal of Cognitive Neuroscience, 22, 474-481. http://doi.org/10.1162/jocn.2009.21215.

Schirmer, A., \& Escoffier, N. (2010). Emotional MMN: Anxiety and heart rate correlate with the ERP signature for auditory change detection. Clinical Neurophysiology, 121(1), 53-59. http://doi.org/ 10.1016/j.clinph.2009.09.029.

Schirmer, A., \& Kotz, S. A. (2006). Beyond the right hemisphere: Brain mechanisms mediating vocal emotional processing. Trends in Cognitive Sciences, 10(1), 24-30. http://doi.org/10.1016/ j.tics.2005.11.009.

Schirmer, A., Striano, T., \& Friederici, A. D. (2005). Sex differences in the preattentive processing of vocal emotional expressions. NeuroReport, 16(6), 635-639, 00001756-200504250-00024 [pii].

Schröder, M. (2003). Experimental study of affect bursts. Speech Communication, 40(1-2), 99-116. http://dx.doi.org/10.1016/ S0167-6393(02)00078-X.

Scott, S. K., Lavan, N., Chen, S., \& McGettigan, C. (2014). The social life of laughter. Trends in Cognitive Sciences, 18(12), 618-620. http://doi.org/10.1016/j.tics.2014.09.002.

Scott, S. K., Sauter, D. A., \& McGettigan, C. (2009). Brain mechanisms for processing perceived emotional vocalizations in humans. In S. Brudzynski (Ed.), Handbook of mammalian vocalizations (pp. 187-198). Oxford: Academic Press.

Sergerie, K., Chochol, C., \& Armony, J. L. (2008). The role of the amygdala in emotional processing: A quantitative metaanalysis of functional neuroimaging studies. Neuroscience and Biobehavioral Reviews, 32(4), 811-830. http://doi.org/10.1016/j. neubiorev.2007.12.002.

Shahin, A. J., Picton, T. W., \& Miller, L. M. (2009). Brain oscillations during semantic evaluation of speech. Brain and Cognition, 70(3), 259-266. http://dx.doi.org/10.1016/j.bandc.2009.02.008.

Smith, N. K., Cacioppo, J. T., Larsen, J. T., \& Chartrand, T. L. (2003). May I have your attention, please: Electrocortical responses to positive and negative stimuli. Neuropsychologia, 41(2), 171-183. http://dx.doi.org/10.1016/S0028-3932(02)00147-1.

Stefanics, G., Csukly, G., Komlósi, S., Czobor, P., \& Czigler, I. (2012). Processing of unattended facial emotions: A visual mismatch negativity study. NeuroImage, 59(3), 3042-3049. http://doi.org/10.1016/j.neuroimage.2011.10.041.

Stothart, G., \& Kazanina, N. (2013). Oscillatory characteristics of the visual mismatch negativity: What evoked potentials aren't telling us. Frontiers in Human Neuroscience, 7, 426. http://doi.org/ 10.3389/fnhum.2013.00426.

Symons, A. E., El-Deredy, W., Schwartze, M., \& Kotz, S. A. (2016). The functional role of neural oscillations in non-verbal emotional communication. Frontiers in Human Neuroscience, 10, 239. http://doi.org/10.3389/fnhum.2016.00239.

Tallon-Baudry, C., \& Bertrand, O. (1999). Oscillatory gamma activity in humans and its role in object representation. Trends in Cognitive Sciences, 3(4), 151-162. http://dx.doi.org/10.1016/ S1364-6613(99)01299-1. 
Thonnessen, H., Boers, F., Dammers, J., Chen, Y. H., Norra, C., \& Mathiak, K. (2010). Early sensory encoding of affective prosody: Neuromagnetic tomography of emotional category changes. NeuroImage, 50(1), 250-259. http://doi.org/10.1016/j. neuroimage.2009.11.082.

Todd, J., Michie, P. T., Schall, U., Karayanidis, F., Yabe, H., \& Näätänen, R. (2008). Deviant matters: Duration, frequency, and intensity deviants reveal different patterns of mismatch negativity reduction in early and late schizophrenia. Biological Psychiatry, 63(1), 58-64. http://doi.org/10.1016/j.biopsych.2007. 02.016.

Todd, J., Michie, P. T., Schall, U., Ward, P. B., \& Catts, S. V. (2012). Mismatch negativity (MMN) reduction in schizophreniaimpaired prediction-error generation, estimation or salience? International Journal of Psychophysiology, 83(2), 222-231. http:// doi.org/10.1016/j.ijpsycho.2011.10.003.

van Ede, F., Jensen, O., \& Maris, E. (2010). Tactile expectation modulates pre-stimulus beta-band oscillations in human sensorimotor cortex. NeuroImage, 51(2), 867-876. http://doi. org/10.1016/j.neuroimage.2010.02.053.

Wacongne, C., Changeux, J.-P., \& Dehaene, S. (2012). A neuronal model of predictive coding accounting for the mismatch negativity. Journal of Neuroscience, 32(11), 3665-3678. http://doi. org/10.1523/JNEUROSCI.5003-11.2012.
Warren, J. E., Sauter, D. A., Eisner, F., Wiland, J., Dresner, M. A., Wise, R. J. S., ... Scott, S. K. (2006). Positive emotions preferentially engage an auditory-motor "mirror" system. The Journal of Neuroscience, 26(50), 13067-13075. http://doi.org/10. 1523/JNEUROSCI.3907-06.2006.

Weiss, S., \& Mueller, H. M. (2012). "Too many betas do not spoil the broth": The role of beta brain oscillations in language processing. Frontiers in Psychology, 3(201). http://doi.org/10. 3389/fpsyg.2012.00201.

Weisz, N., Wühle, A., Monittola, G., Demarchi, G., Frey, J., Popov, T., et al. (2014). Prestimulus oscillatory power and connectivity patterns predispose conscious somatosensory perception. Proceedings of the National Academy of Sciences of the United States of America, 111(4), E417-E425. http://doi.org/10. 1073/pnas.1317267111.

Wildgruber, D., Ackermann, H., Kreifelts, B., \& Ethofer, T. (2006). Cerebral processing of linguistic and emotional prosody: fMRI studies. Progress in Brain Research, 156, 249-268. http:// dx.doi.org/10.1016/S0079-6123(06)56013-3.

Winkler, I., \& Czigler, I. (2012). Evidence from auditory and visual event-related potential (ERP) studies of deviance detection (MMN and VMMN) linking predictive coding theories and perceptual object representations. International Journal of Psychophysiology, 83(2), 132-143. http://doi.org/10.1016/j.ijpsycho.2011.10.001. 